\title{
Determination of induced stress condition inside Pilar Norte sector
}

\author{
C. Orrego Codelco Chile, Chile \\ D. Cuello Codelco Chile, Chile \\ E. Rojas Codelco Chile, Chile
}

\begin{abstract}
Pilar Norte is a new productive sector situated between the Esmeralda and Reservas Norte sectors, forming a pillar between the undercut fronts of these two adjacent mining sectors. Undercutting of the Pilar Norte panel cave started in August 2009 and production commenced in June 2010. A large stress variation is expected due to the pillar geometry; three-dimensional elastic models are being used to understand the stress conditions throughout the pillar and to assist in forecasting possible geotechnical scenarios during production. This paper provides a methodology to calibrate and validate the model in comparison to measured stresses and observations made in the field. In addition, an application of the model to compare with seismicity experienced is presented.
\end{abstract}

\section{Introduction}

Having a safe and economical exploitation is the main objective in planning a new mining sector. To achieve this, a good understanding of rock mass condition, stress regime and how they are altered by mining is required. When mining takes place inside a geometrical singularity such as a pillar left by two large caves, a large variation in stresses is expected. Since stress measurement is limited to some areas inside the pillar, the areas where stress measurements not taken need to be determined with the assistance of numerical modelling tools. The variation of the stress condition inside this pillar will generate areas with large stress concentration resulting in geomechanical hazards. Areas where large stresses are present are more likely to experience a more active seismic response. As for any rock mechanics design, there is no direct method to address the geomechanical conditions inside the Pilar Norte sector. Therefore, the application of numerical modelling is a valuable tool to forecast possible geotechnical scenarios due to mining.

\section{Site investigation}

\subsection{Pilar Norte sector}

Pilar Norte sector is an important project within the El Teniente Mine that will be producing 17,000 t per day with a $1.32 \%$ grade in copper and $0.032 \%$ Molybdenum. Mining is done by applying an advance panel caving with a strategy of four independent blocks. The undercutting process started in August 2009 and production took place in June 2010. Pilar Norte, as the name implies, is a pillar formed by the interaction of two large caves; Esmeralda and Reservas Norte sectors (Figure 1). Pilar Norte and Reservas Norte sectors are located in the same elevation and $90 \mathrm{~m}$ below the Esmeralda undercut level. Previous experiences in similar geometrical conditions have shown that the rock mass will experience a complex seismic response.

During December 2009, when undercutting reached 4,000 $\mathrm{m}^{2}$, a large seismic event, $60 \mathrm{~m}$ below undercut level, resulted in a rockburst that affected most levels at the Pilar Norte sector. As a consequence of this rockburst undercutting activities were stopped. However, in January 2010, a new rockburst occurred generated by a large seismic event located $30 \mathrm{~m}$ above the undercut level and $100 \mathrm{~m}$ away from the undercut front. Unlike previous rockbursts, this event was not related to the undercutting process and was more likely to have been caused by mining activities at the northern edge of the Esmeralda sector. 


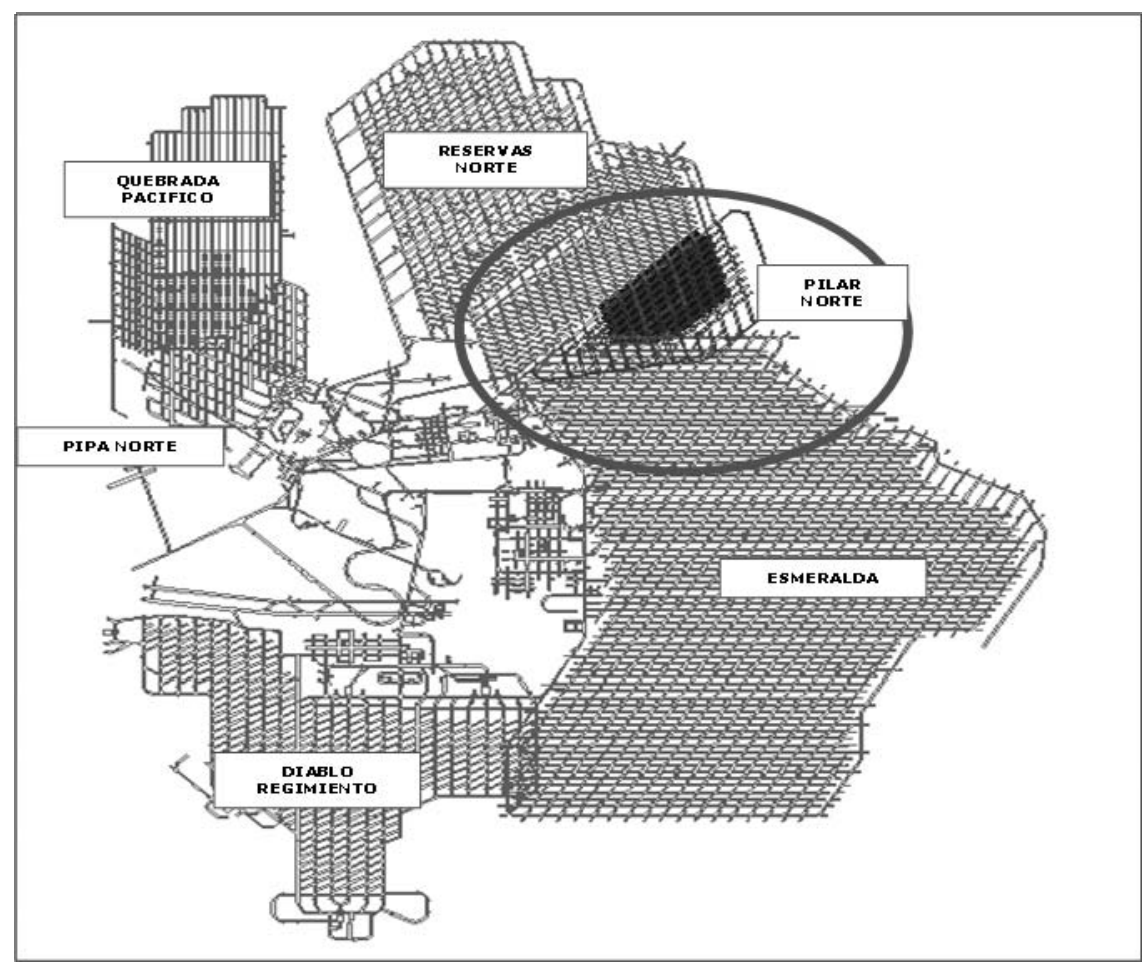

\section{Figure 1 Plan view of EI Teniente mine sectors}

\subsection{Geological, geotechnical and structural conditions}

Pilar Norte geology is very complex, because of the presence of at least eight different types of lithology which can be distinguished within a small area. Among these, El Teniente mafic complex (CMET) corresponds to the host rock mass, within which two felsic intrusives can be observed: dioritic porphyry and Andesitic porphyry. Together with these bodies, several breccias can be distinguished (Figure 2).

Two preferred orientations for the structural domains were identified. They correspond to $\mathrm{N} 20^{\circ} \mathrm{E}$ and $\mathrm{N} 50^{\circ} \mathrm{W}$ and both systems present a sub-vertical dip between $70-90^{\circ}$. In terms of major faults the $\mathrm{W}$ and $\mathrm{B}$ systems are the most important, they have an orientation of $\mathrm{N} 20^{\circ} \mathrm{E}$ and $\mathrm{N} 50^{\circ} \mathrm{W}$ respectively (Figure 2).

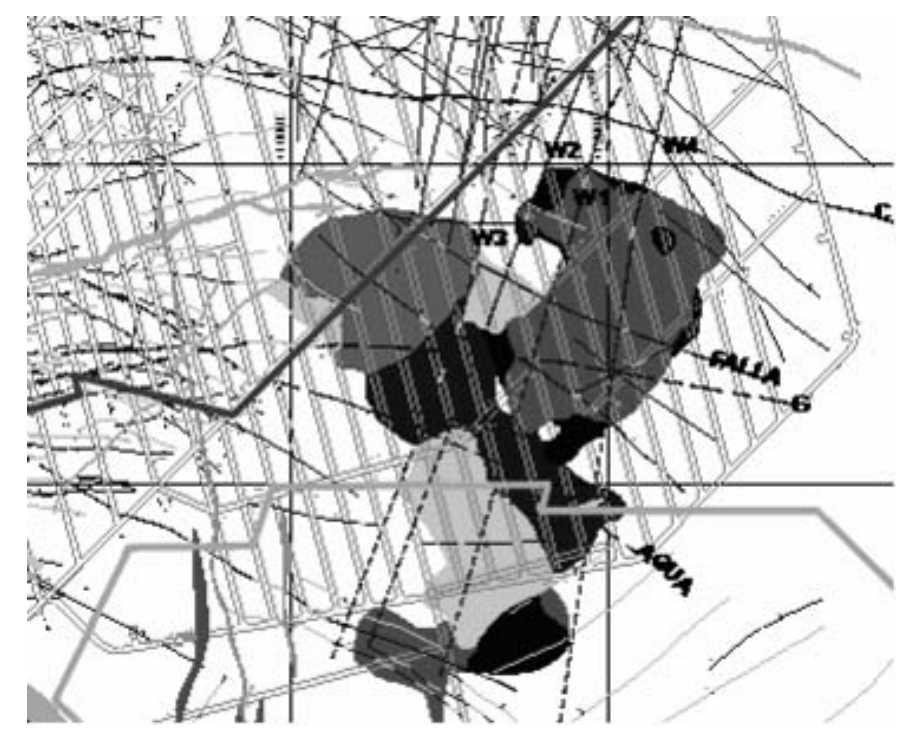

Figure 2 Geological map of undercut level 


\subsection{In situ stress conditions}

Stresses were measured in different positions of the undercut, production and transport levels, using the hollow inclusion method. Additionally, acoustic emission technique was used to reach places where no development drives were available. A total of six stress measurements were completed in this study. The left graph of Figure 3 represents the principal stress magnitudes and the right side of Figure 3 represents a stereographic projection for principal stresses.

Major principle stress at the undercut level and below has a mean value of $60 \mathrm{MPa}$ with a sub horizontal east-west orientation. $\mathrm{S}_{1}$ exhibits a little scatter in inclination and a $40^{\circ}$ scatter for its trend. The other two principal components show a larger scatter in inclination but lower scatter in their trends.

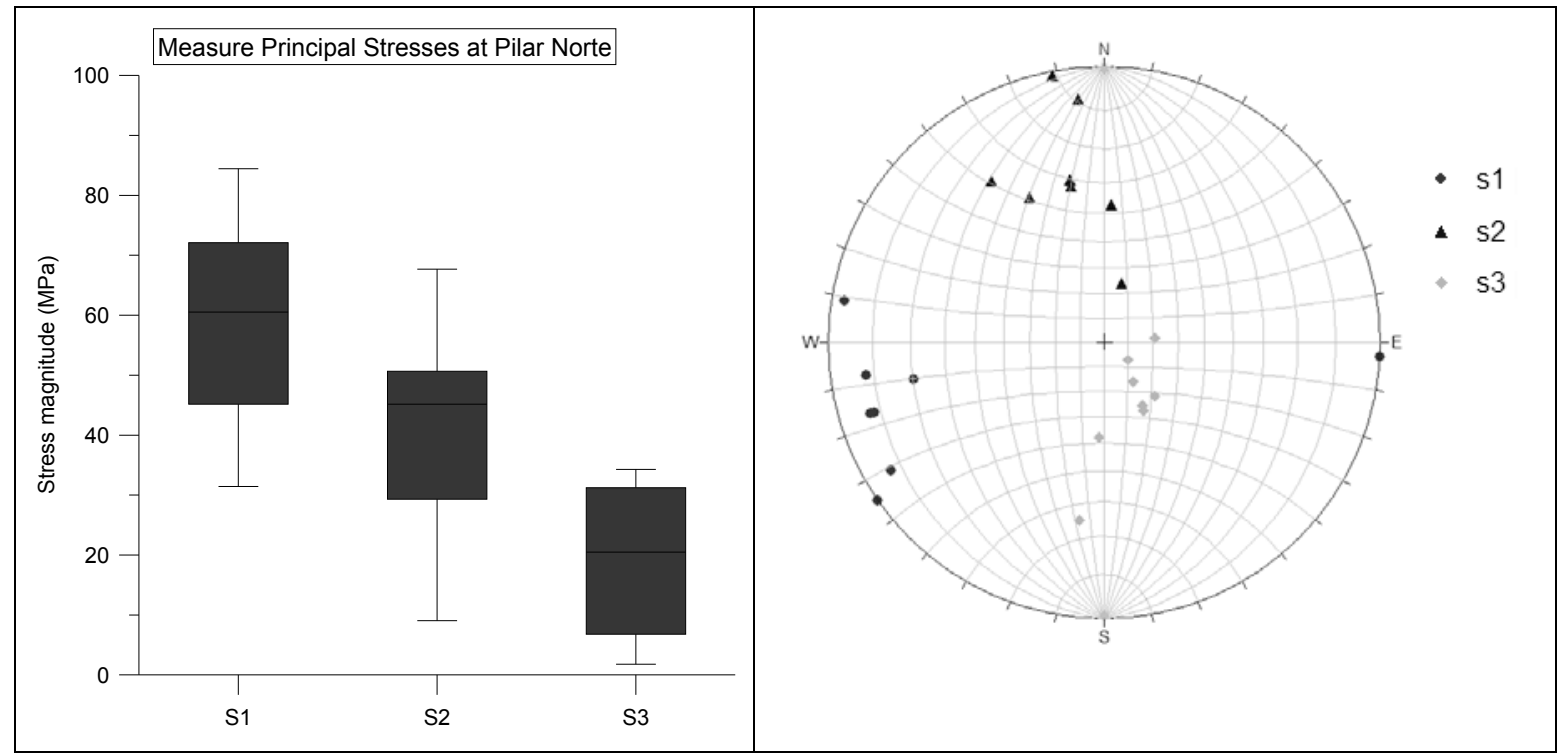

Figure 3 Left: magnitude distribution of principal stresses; right: stereographic projection of principal stresses

\subsection{Chronologic seismic response}

Seismic activity is unavoidable and is inherent to the caving propagation process in caving mines which are placed in hard and competent rocks. Since 1999, when the geometry of Pilar Norte was formed, seismic events have been occurring inside the pillar, even without any mining activity taking place in this sector. Nevertheless, the most active periods for seismicity have occurred when geometrical changes have taken place close to the pillar, especially when the Pilar Norte sector has been 'strangulated'.

A simplified analysis is shown in Figure 4 where only large events $\left(\mathrm{M}_{\text {Local }} \geq 1.0\right)$ are presented; here the large events have been sorted by elevation and time.

After the geometrical formation of Pilar Norte in 1999, during 2000-2003 (Figure 5a), most of the large events were concentrated above the Esmeralda undercut level. During 2004, as the Esmeralda sector started to grow towards the north-east, known as 'Extensión HW' (Figure 5b), and the same seismic response in terms of preferential elevation for large events was noted. During 2005 and 2006, a new mining area was incorporated at the north side of Esmeralda (Figure 5c). This new mining area shrank the Pilar Norte generating a more active seismic response, and seismic events migrating below the Esmeralda undercut level. Until the end of 2009, most large events occurred at higher elevations, however, towards the end of 2009 and the beginning of 2010 a new area at the north edge of Esmeralda was mined out (Figure 5d). Due to the strangulation of Pilar Norte, an increasing number of large events were generated and most of them occurred close to the undercut level of Pilar Norte. Finally, during the same period, two rockbursts occurred inside Pilar Norte. 




Figure 4 Frequency of relevant seismic events at different elevations 

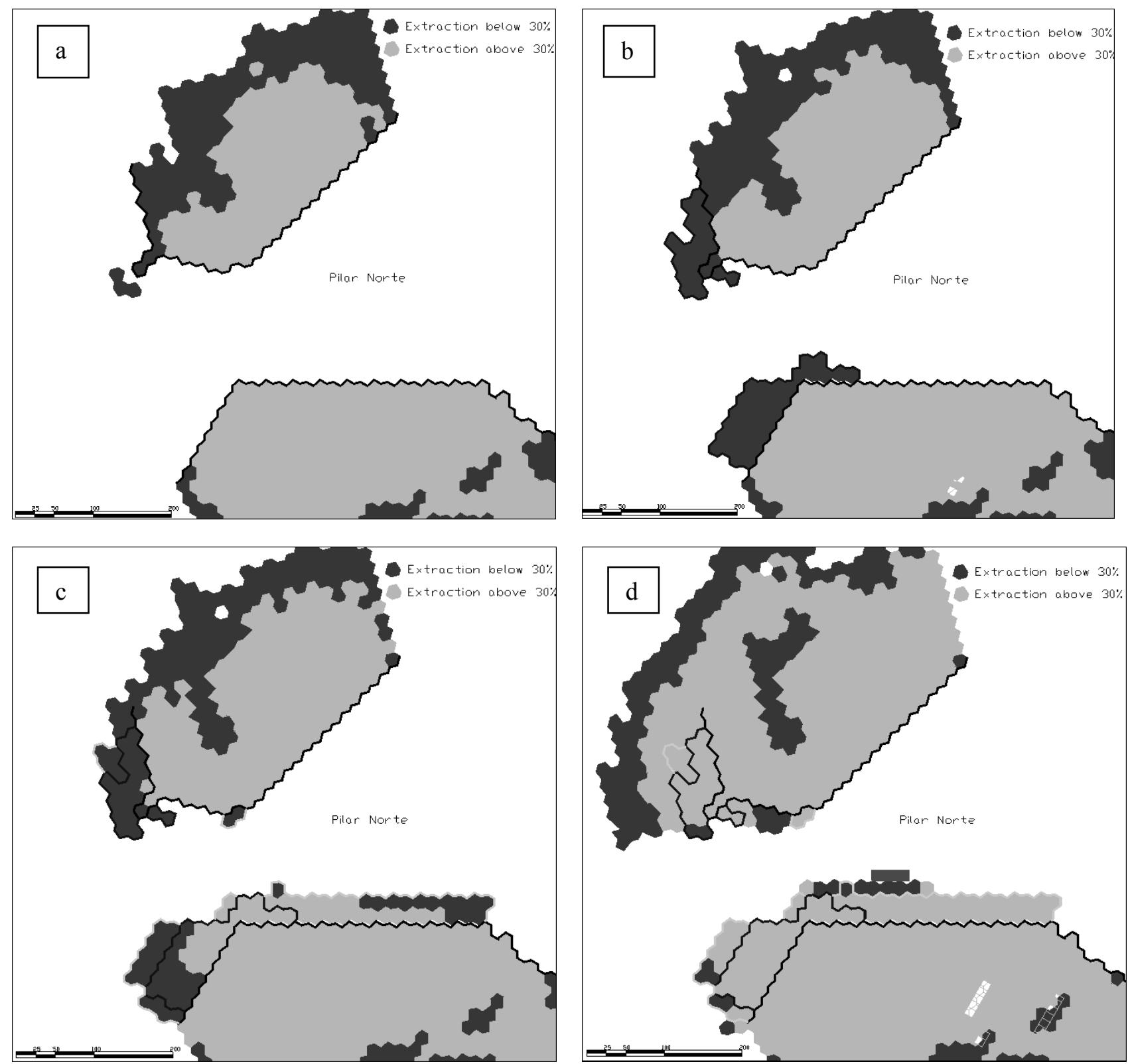

Figure 5 Evolution of the mining fronts in Reservas Norte and Esmeralda sectors, the dark grey dots represent the extraction below $30 \%$ of block height and the lighter grey dots represent the extraction above $30 \%$ of the block height: a) January 2004; b) January 2005; c) January 2006; d) January 2010

\section{General approach}

Several three-dimensional numerical models were performed in order to carry out three main tasks. First, validate the use of a local model based on a large scale numerical model (Figure 6). Second, once the local model showed consistent results when compared with a large scale model, several inputs were tested until minimized error between stress measurements and model predictions was achieved. Finally, the calibrated local model was validated against observations made in the field. 


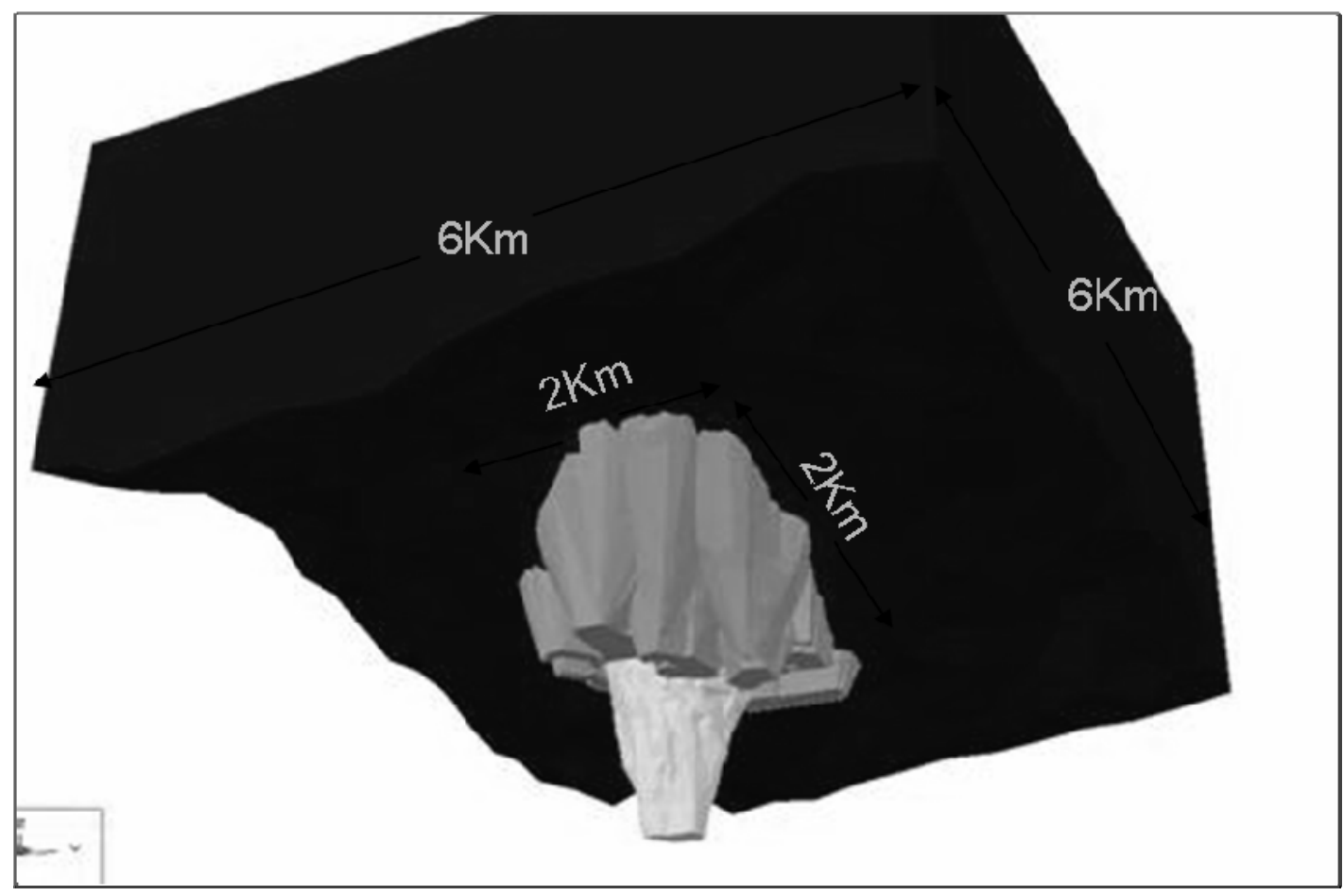

Figure 6 View of the large scale model

\subsection{Numerical modelling}

The geotechnical condition inside Pilar Norte was investigated by carrying out several Map3D Models. The Map3D model was chosen due to the complex geometry of the area of interest and the need to capture the three dimensional effect given by the interaction of the adjacent caves that formed the pillar.

\subsubsection{Large-scale model to local model}

The large scale model was conceived to provide a general idea about stress conditions around the whole mine. Nevertheless, when applied to specific areas such as Pilar Norte, the model required a major level of details, including a layout of the area of interest and a better geometrical definition of the cave. Therefore, having a model that captures the general mine condition and enables a major level of detail without compromising the time calculation is highly desirable. Based on the above, a local model was built, calibrated and validated. To compare the local model response against the large-scale model, the volume of the pillar was divided into $15 \times 15$ blocks. Thereafter, the stress tensor at all block centroid was calculated. As the large-scale model encompassed all cave geometries of the mine, including the Brecha Braden, the local model aimed to include only the geometries that could affect the stress redistribution inside Pilar Norte.

\subsubsection{Pilar Norte block model}

Pilar Norte volume covers approximately $27,000,000 \mathrm{~m}^{3}$. A block model was created in Vulcan, by dividing the volume of the pillar into $15 \times 15 \mathrm{~mm}$ blocks as can be seen in Figure 7. Each centroid of this block model was then entered into Map3D as data file format, which correspond to a list of the coordinate locations where the results are to be calculated. 


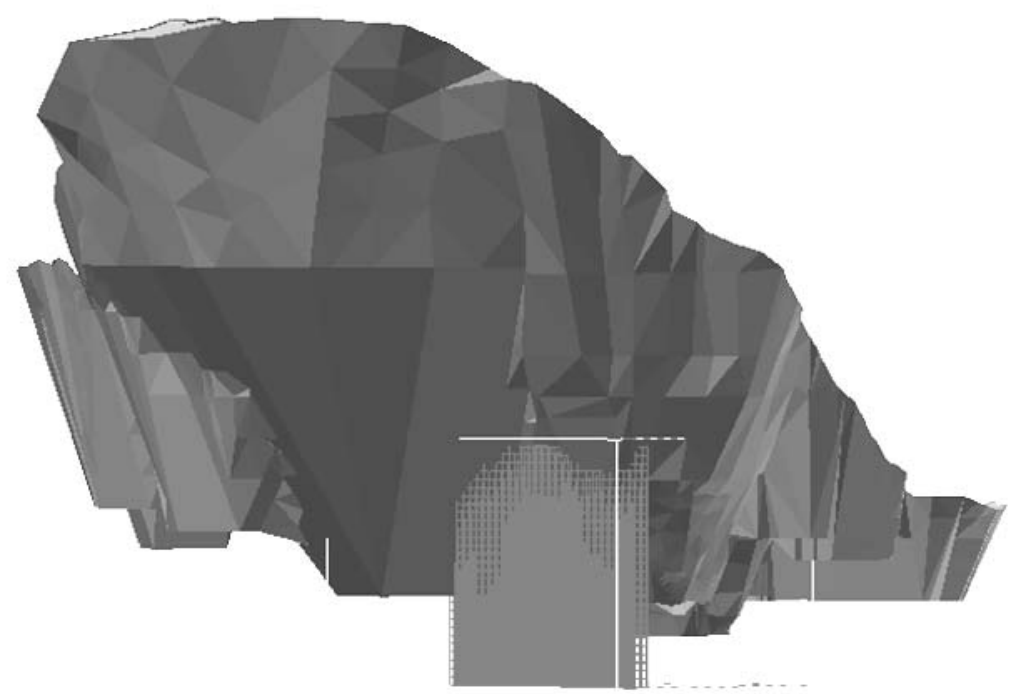

Figure 7 Block model for Pilar Norte

\subsubsection{Local model}

The local model includes geometries for surface topography, and caves for Reservas Norte, Esmeralda, Teniente 5, and for the Pilar Norte sector. Additionally, a higher level of geometrical details was incorporated for the pillar. Here, the undercut, production ventilation and transportation levels were included in the model for a better description of the local conditions of the pillar (Figure 8).

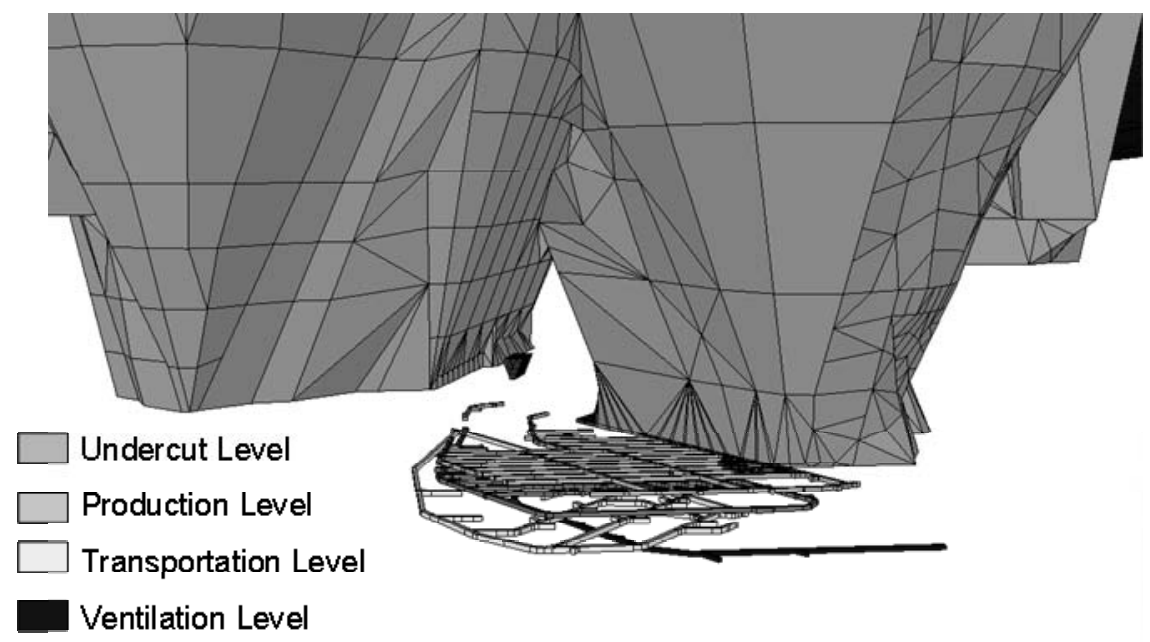

Figure 8 View of the layout included in the local model

\subsubsection{Local model geometry}

The final geometry of the local model was defined by comparing the stresses calculated at the centroids of all blocks inside the Pilar Norte block model. The same procedure was then applied to compare the impact of the Brecha Braden in the Pilar Norte area. It was observed that the impact on stresses inside the Pilar Norte, given by the inclusion of the Brecha Braden, and the geometrical modification altered the stress tensor by 2.7 and $6.3 \%$ respectively; both effects can be seen in Figure 9. Finally, the local model reduces the number of boundary elements from 250,000 in the large scale model to 50,000, which significantly reduces the computation time. 

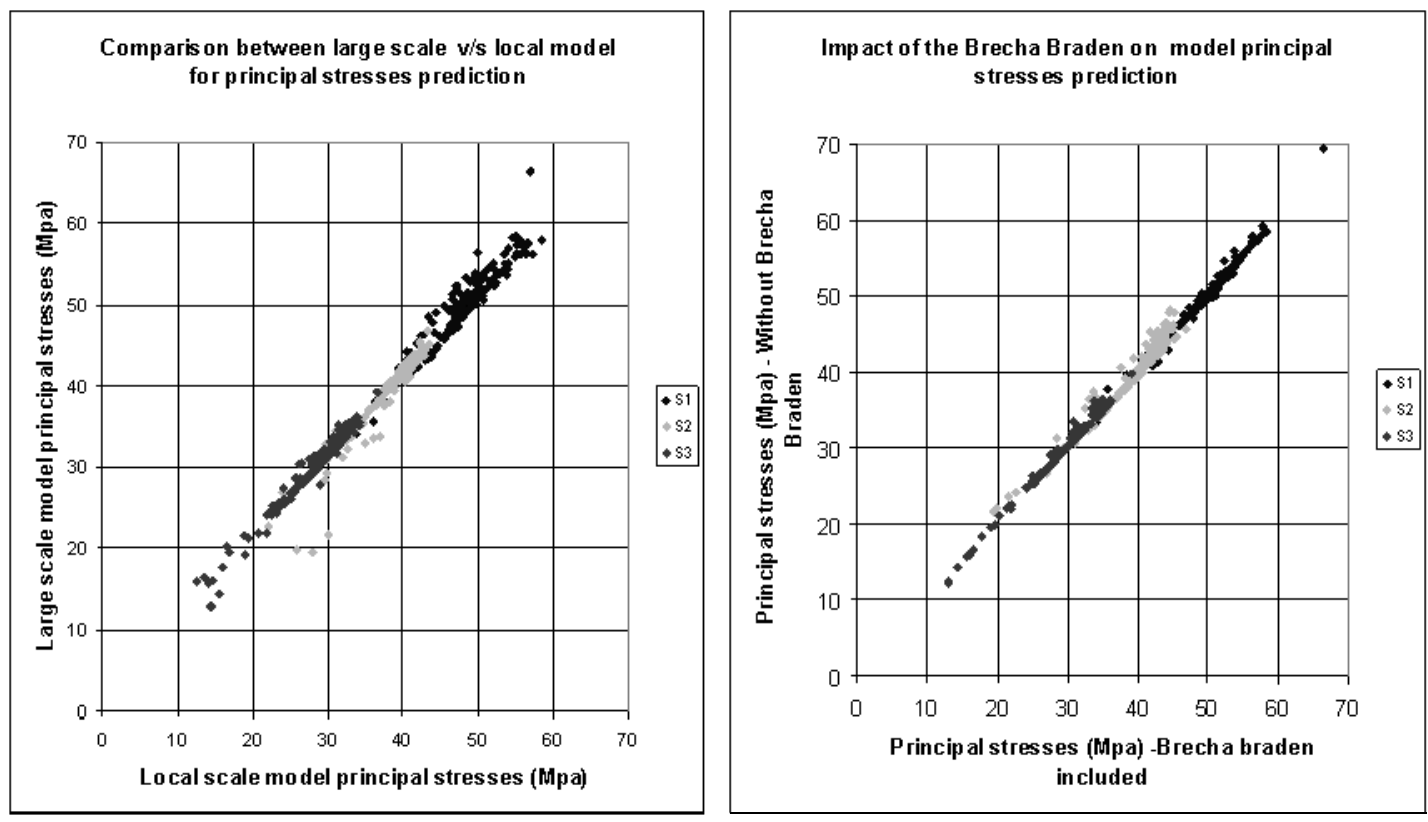

Figure 9 Variation of stresses given by geometrical changes in the model

\subsubsection{Calibration}

Calibration of the Map3D model was required to ensure that the model simulates the actual stress conditions and the results from the model could be used to estimate the response at different times so appropriate recommendations can be made regarding critical geotechnical issues inside Pilar Norte. As part of the study, a series of cases were run, taking into account several options including 21 different pre-mining stress assumptions. The model was tested against the stress measurement by comparing the error between model predicted stress tensor and stresses measured at Pilar Norte. The option giving the lowest error was kept as an input for the model (Figure 10).

One of the main assumptions inherent in the stress analysis procedure is that measurements are accurate and representative of the locations in which they are made. However, experience indicates that despite the use of the best experimental technique there will be an error attributable to the heterogeneity of the rock mass. Hence, before using them for calibration purposes, the consistency of these measurements need to be tested by measuring the error of all tests performed (three at each hole) to define the average reading. Once, the consistency of the stress measurement is established, it may be used to calibrate the model; only the stress measurements with an error of less than $35 \%$ were included for this study.

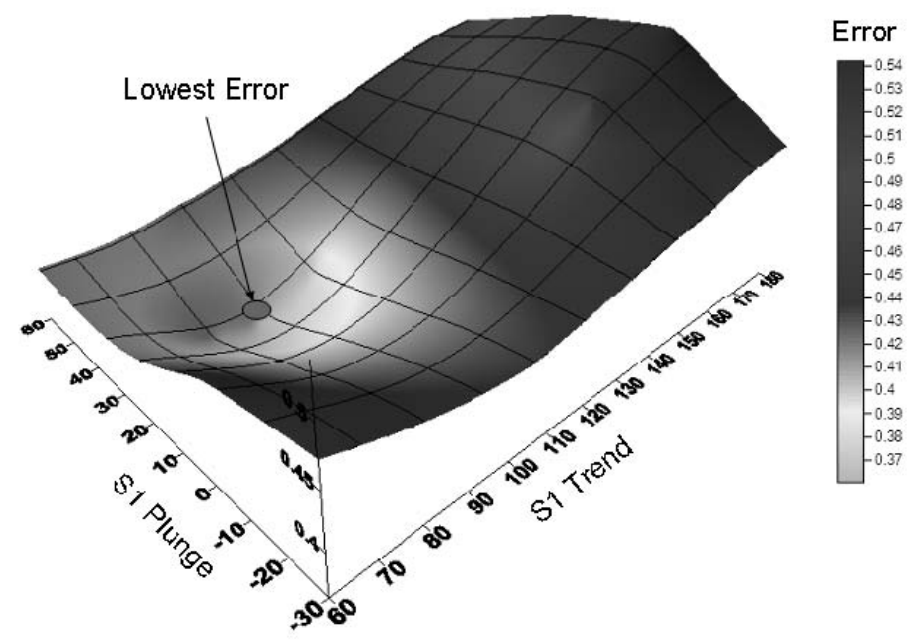

Figure 10 Error surface for input stress in model 


\subsubsection{Validation}

At Pilar Norte sector, the validation process of the model can be achieved by comparing model predictions to observational data such as orepass instability, rock mass damage at the undercut, and seismic response to mining. Since models only predict stress and strain, it is necessary to be more specific regarding how to compare model predictions with observations. When using elastic models (Wiles, 2010), normally three approaches can be taken to compare model predictions to observational data, as shown in Figure 11:

- Likelihood of failure - here model predicted stress states below a certain failure criteria are unlikely, whereas those above are likely.

- New accumulating damage - here increasing stresses tend to drive failure resulting in the appearance of new damage, whereas decreasing stresses do not.

- Nature of failure (energy, moment, ERR) - here large deformation failures result in large amounts of energy released during the failure process causing violent potential failures.
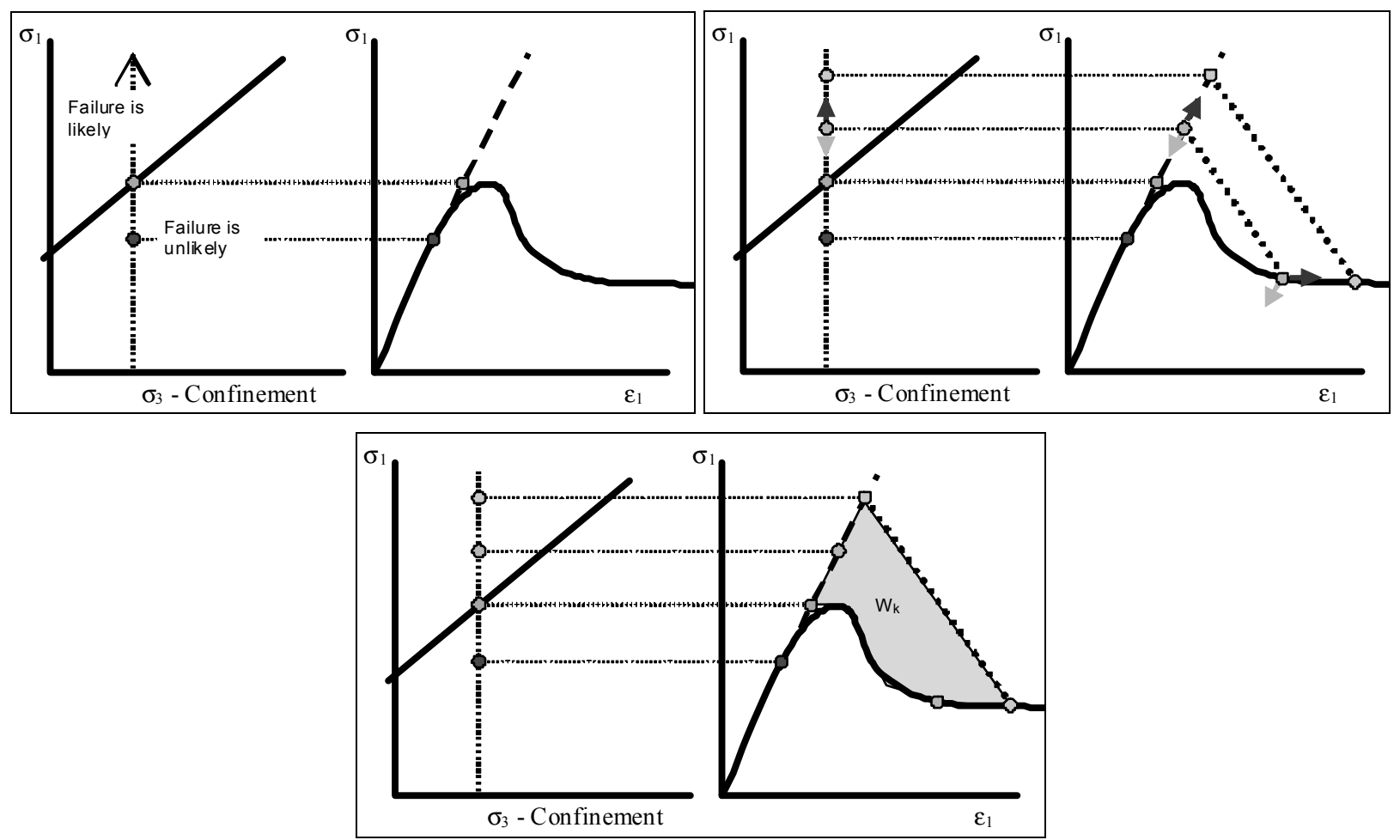

Figure 11 Different ways to make comparisons between model predictions and observations

\subsubsection{Orepass stability}

At Pilar Norte, during the construction phase, three orepasses experienced stability issues (Figure 12), Rojas et al. (2004), after an extensive review of ore pass instability at El Teniente, found that stability issues generally took place when the ratio S1 exceeds 0.4. When this criterion was applied for Pilar Norte, at the locations of the Map3D model where ore passes experienced instability, all of them plotted the above criterion. 


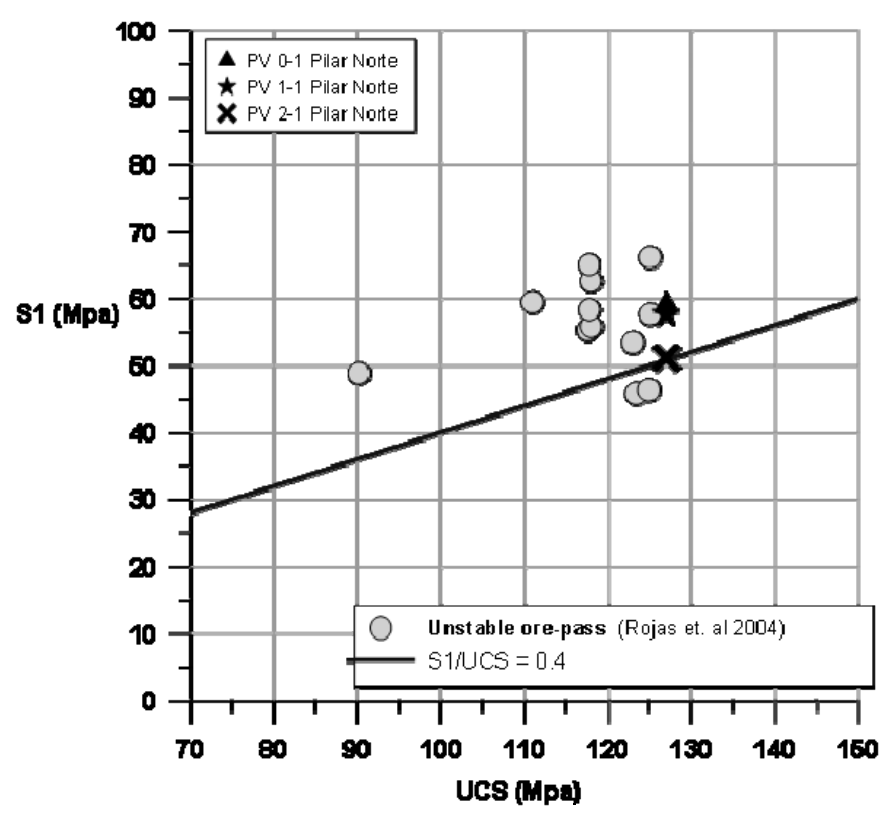

Figure 12 Orepass stress conditions at which instability is prone to occur

\subsubsection{Rock mass damage at the undercut}

A good indicator of rock mass damage at the undercut can be found by inspecting charge holes. When the effect of the abutment stress generates conditions that can damage the rock mass, some evidence such as overbreak and dislocation can be seen inside the charge holes. This damage will impede the charging process of these holes. Figure 13 shows model prediction against observational data. By comparing the location of the damage versus the model prediction it was found that the model over-predicted the damage location by $10 \%$, which represents a reasonable match.

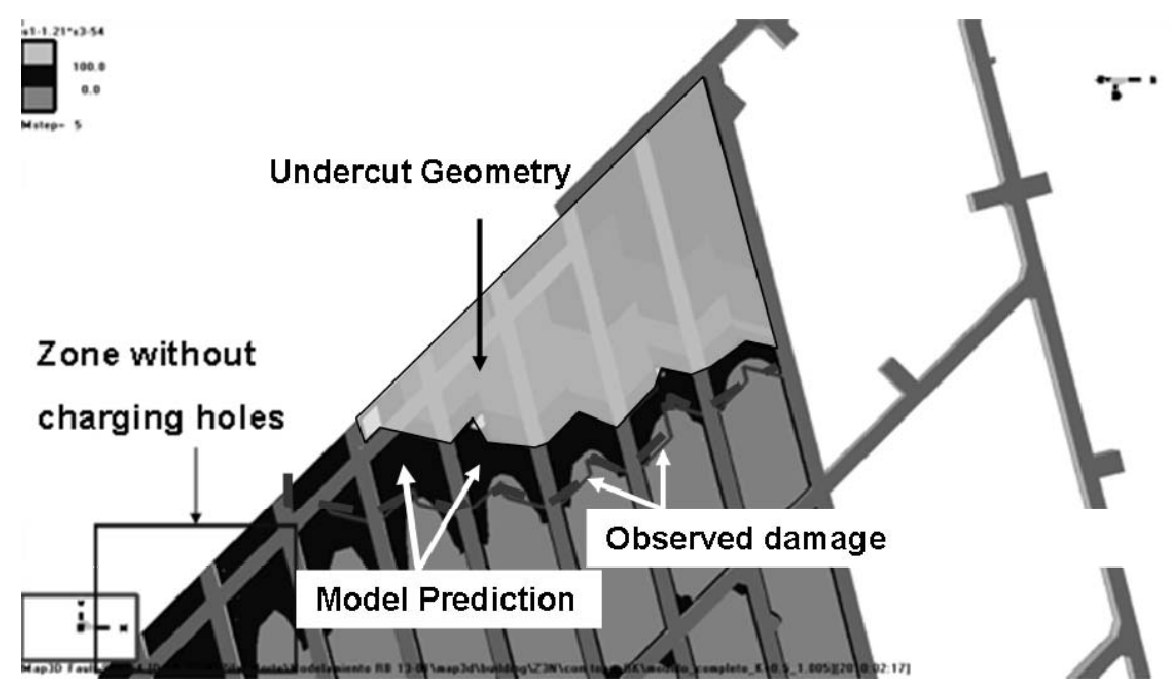

Figure 13 Damaged charge holes at the undercut level and Map3D prediction

\subsubsection{Hydro-fracture information}

Rock mass preconditioning by hydraulic fracturing was performed above the undercut level at Pilar Norte. The information from 19 holes, with an average length of $100 \mathrm{~m}$ and fractures generated each $1.5 \mathrm{~m}$, was used as a source to validate the numerical model in this study. The magnitude for the principal minor stress (S3) at each location where fractures were generated can be compared with the model prediction as shown in Figure 14a. Additionally, a test was performed for some hydrofractures inside the Pilar Norte sector in order to determine the orientation of the principal minor stress; the measured orientation for S3 was compared with model predictions as shown in Figure 14b. 



Figure 14 a) S3 magnitude comparison from hydro-facture and model prediction; b) Trend and plunge for S3 from model prediction and orientation obtained from test

\subsubsection{Seismic response}

\subsubsection{Fault slip}

Although major faults were not modelled explicitly, plane grids were placed to investigate the potential for fault slip. The excess shear stress, defined as $\mathrm{ESS}=\tau-\sigma_{\mathrm{n}} \times \mathrm{u}$, with ' $\mathrm{u}$ ' friction coefficient, and $\sigma_{\mathrm{n}}$ the normal stress acting on the plane, was used to investigate the potential for fault slip. It was possible to observe that faults are prone to slip on the upper part of the pillar, but stress conditions in the lower levels show high clamping (normal) stresses, which inhibit the occurrence of fault movements. This simple criterion allows a classification of faults in terms of their potential to generate a rockburst. In Figure 15a, it can be seen that the W3 fault has the potential to slip at the top close to the south wall of the Reservas Norte cavity. In contrast, C Fault has no slip potential (Figure 15b).

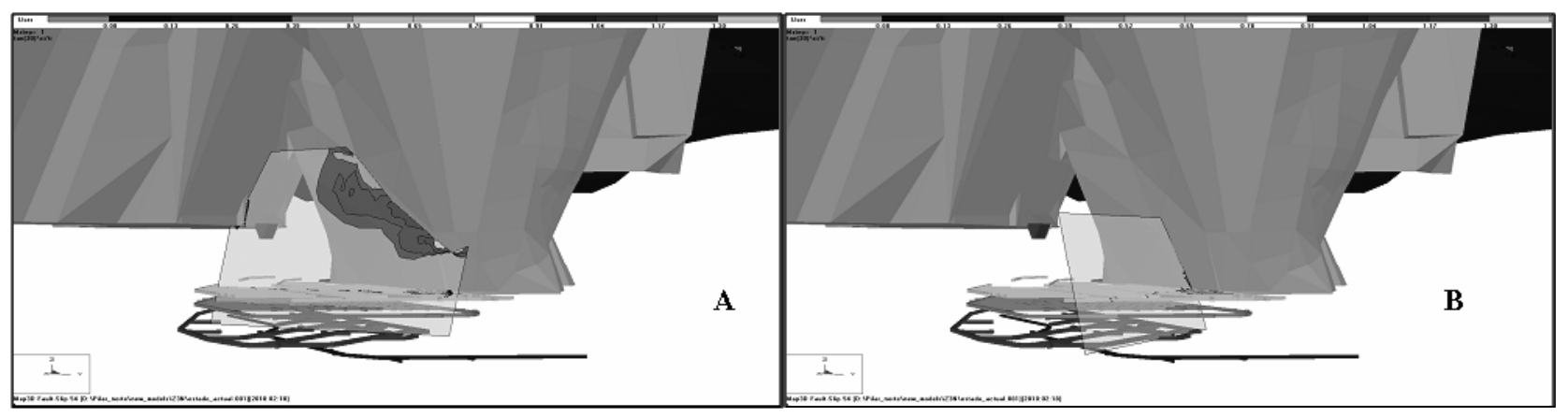

Figure 15 ESS conditions occurring on two grids representing Fault 'W3' and 'C' respectively

\subsubsection{New accumulating damage and seismicity}

A great amount of seismicity has been recorded at Pilar Norte, at the location where events have occurred the stress condition was calculated using 7,000 events and then a lower limit containing $90 \%$ of the information was established by the following criterion: $S 1=1.05 \times S 3+23$ (Figure 16), similar criterion has been reported by other authors as shown by Rubio et al. (2007). This criterion was used to identify areas where sudden increases in $\Delta \sigma_{1}$ for a given mining step would indicate a higher likelihood of seismicity occurring. 


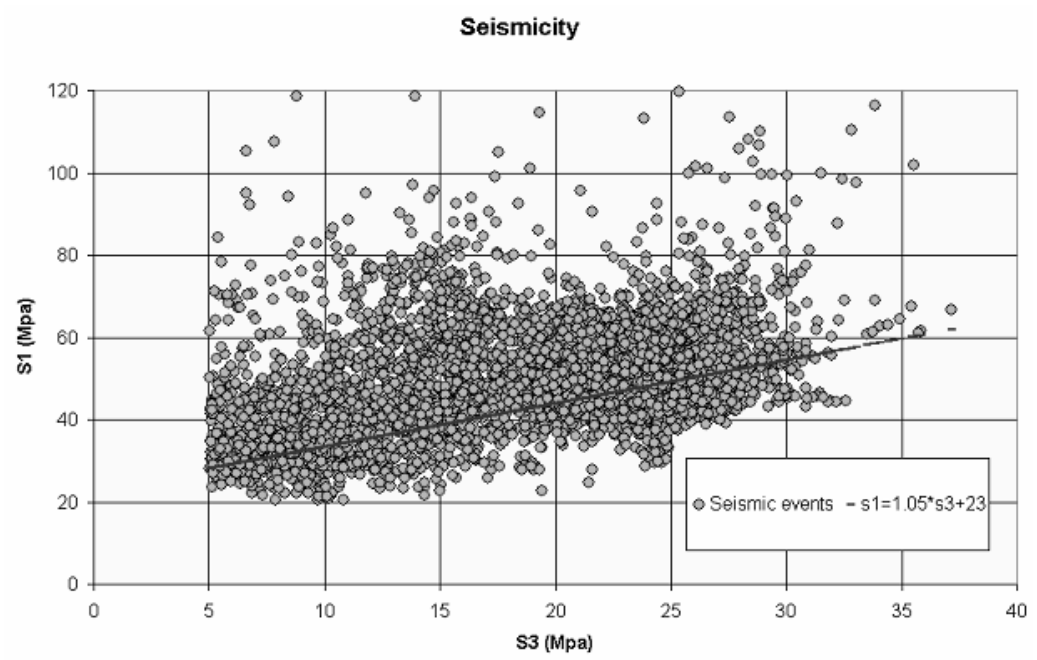

Figure 16 Stress conditions at which seismic events occur

\section{Case studies}

The likelihood of achieving a large magnitude event was investigated by comparing two cases where geometrical changes inside the pillar caused the occurrence of large magnitude events.

\subsection{Case study 1}

During December 2009, while undercutting was progressing, a rockburst took place affecting several levels including the undercut, the production and the ventilation levels. A Map3D model was used to investigate possible causes for this rockburst.

\subsection{Case study 2}

A considerable increase in large events took place in January 2010, after a new zone at the north edge of the Esmeralda sector was mined out.

\subsection{Model results}

\subsubsection{Model results studied case 1}

It was found, that fault $\mathrm{C}$ slip was unlikely to have triggered this rockburst due to the high clamping stresses acting on the fault plane (Figure 17). However, when new accumulative damage based on the criterion show in Figure 18 was tested, it was possible to see a match between the increments of $\Delta \sigma_{1}$ location and the position of the focal event that caused the rockburst. Here, the rupture surface can be defined as the most likely orientation from the model predicted principal stress state.

Once the candidate surface predicted by the model was determined by considering the surface location at [45- $\varphi / 2]$ from the direction of $\sigma_{1}$, Map3D was run to consider the proposed failure as a planar rupture shape. A trial calculation for the pictured rupture provided a model calculated potency of 62.12 . By using the formula proposed by Gaete (2009), the moment magnitude for the event was calculated as follows:

$$
\mathrm{m}=0.67 * \log 10(62.12)+0.95=2.15
$$

In spite of the fact that the $2.15 \mathrm{Mw}$ resulted in a larger magnitude event when compared with the actual event size of $1.9 \mathrm{Mw}$, the result showed a reasonable agreement. 


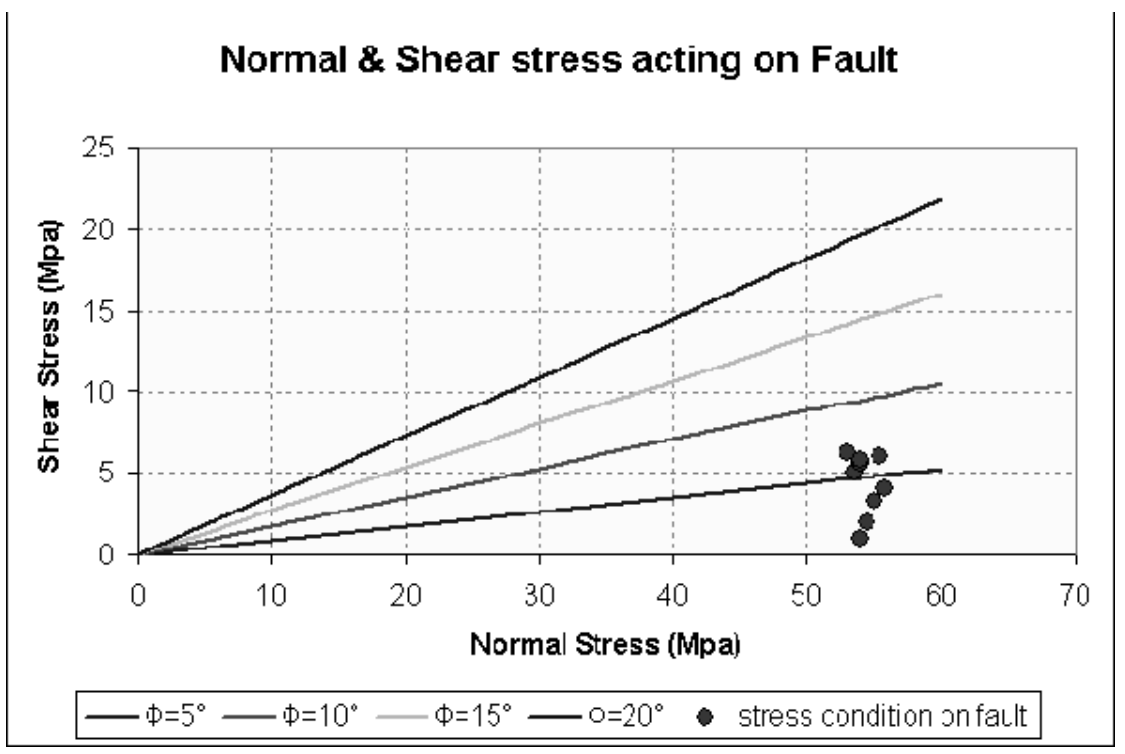

Figure 17 Stress condition on fault ' $C$ '
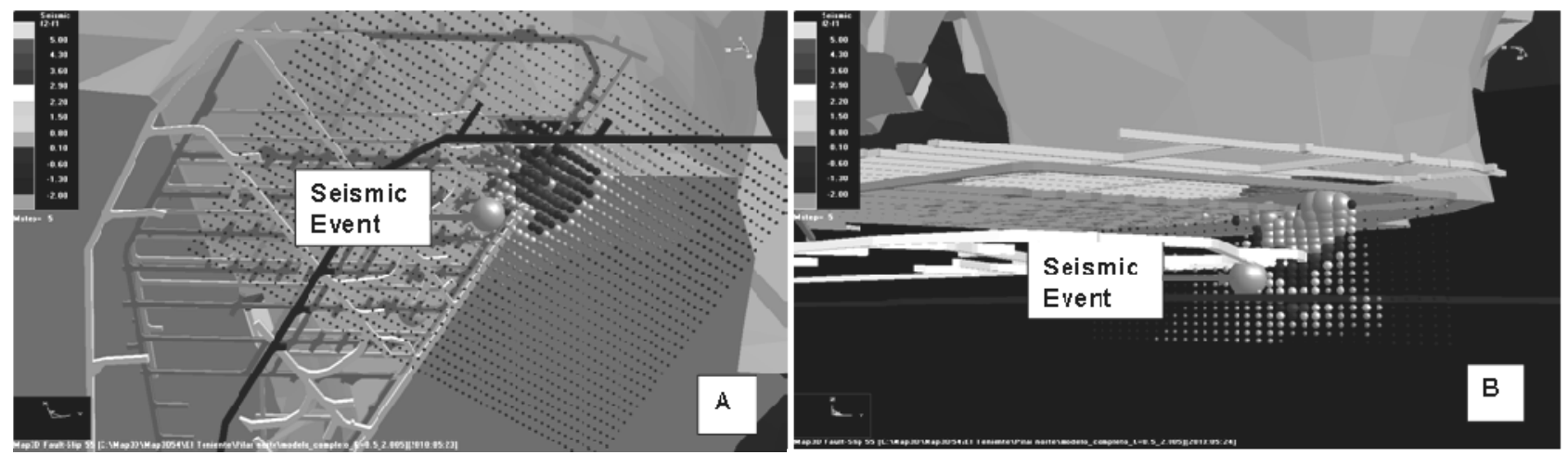

Figure 18 Large increments for $\Delta \sigma_{1}$ location: a) Pilar Norte plan view looking straight up; b) section view looking towards north

\subsubsection{Case study 2 model results}

New accumulative damage based on the criterion shown in Figure 17 was assessed for two months represented in the model by two mining steps. The first step is without mining at the north edge of the Esmeralda sector; the second step includes the new mining zone. As can be appreciated in Figures 19a and $19 \mathrm{~b}$, the areas where the model shows large increments of new accumulative damage for the second mining step, correspond reasonably well to where large events occurred.

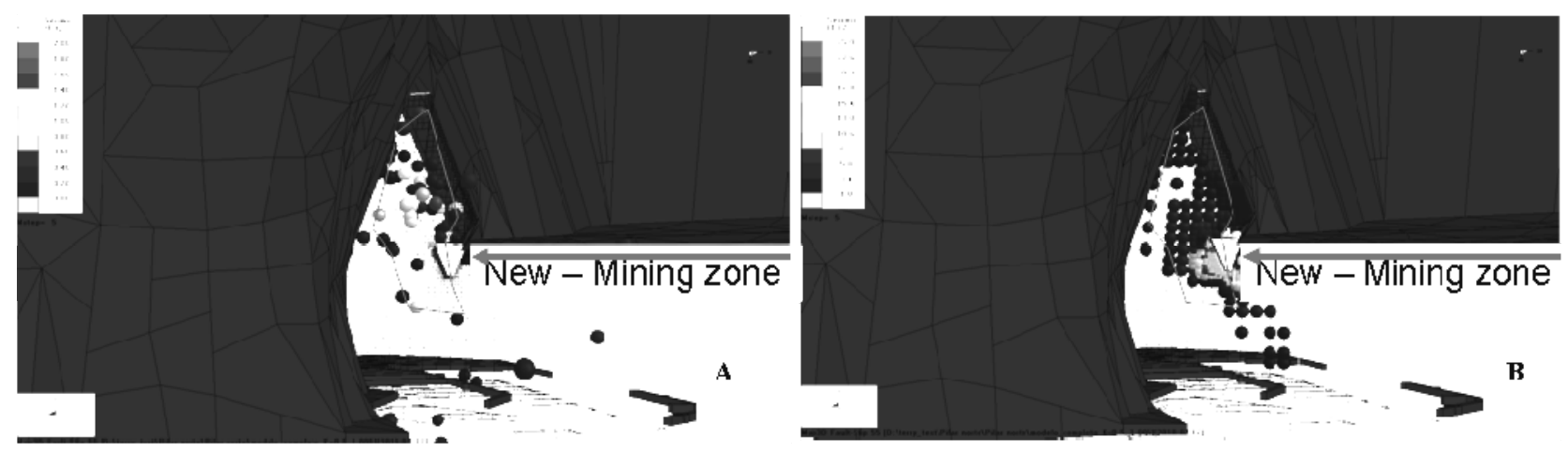

Figure 19 a) Actual large seismic events; b) model prediction for $\Delta \sigma_{1}$ large increments 


\section{Conclusions}

A three-dimensional model has been developed to look at the likely rock mass conditions associated with mining at Pilar Norte. For this work, a local model was built and then the local model was calibrated and validated with information including: Stress measurement, hydrofracturing propagation fracture pressure, rock mass damage and recorded seismicity.

The methodology shown in this paper and the results obtained have shown that this approach can be used to assist the process of managing risks associated with complex mining geometries such as the case of Pilar Norte.

\section{Acknowledgements}

The authors acknowledge the following people who contributed to the development of the work reported in this paper: Sergio Gaete, Roberto Gonzalez, and Dr Terry Wiles.

\section{References}

Gaete, S. (2009) Seismic hazard Assessment at the Nuevo Nivel Mina, Internal report (SGM-I-018/2009), Codelco Chile - División El Teniente.

Rojas, E., Bonani, A. and Santander, E. (2004) Geomechanical criteria for orepass design - El Teniente Mine, Codelco Chile, in Proceedings Massmin, Santiago, Chile, A. Karzulovic and M.A. Alfaro (eds), pp. 309-314.

Rubio, E. and Napitupulu, D. (2007) Caving performance through integration of micro-seismicity activity and numerical modeling at DOZ - PT Freeport Indonesia, in Proceedings 1st Canada-US Rock Mechanics Symposium, Vancouver, Canada, Taylor \& Francis (eds), pp. 1321-1327.

Wiles, T. (2010) MAP3D Course Notes. 